\title{
Microwave-assisted Embedding of Tissue Culture Cell Monolayers
}

\author{
Kent L. McDonald
}

Electron Microscope Lab, University of California, Berkeley, CA 94720-3330

When cells are grown as a monolayer on a substrate, a useful method of embedding is to retain the monolayer orientation in the polymerized resin. One can then use a good compound light microscope to screen the samples and select certain cells for sectioning..There are a number of ways to do this for conventional embedding methods with epoxy resins [1], but it is more of a challenge when using the microwave for polymerization because resin polymerization is best done under water. However, if cells are grown on plastic, they can be embedded in TAAB polyethylene flatbottom capsules (Ted Pella, Inc., Cat. No. 133) and when the resin is polymerized, the plastic is peeled off and the cells remain in the resin.

Microwave set-up. The microwave used was a Pelco Model 3440, to which had been added a Pelco Model 3430 Power Controller for variable wattage, a Pelco Model 3435 Microwave Vacuum

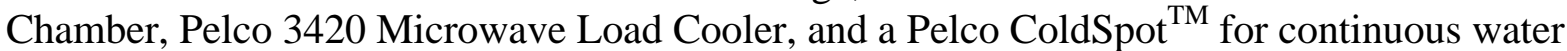
circulation in the microwave cavity. All equipment was from Ted Pella, Inc., Redding, CA. The load cooler temperature was set to $25^{\circ} \mathrm{C}$, the vacuum chamber put directly on the Coldspot, and the variable wattage controller set to 1 , about $100 \mathrm{~W}$.

Cell preparation and handling. Cells are grown on 6-7 mm disks of Aclar plastic film (Ted Pella, Inc., Cat. No. 10501). In our experience, Thermanox or other plastics do not work as well as Aclar. The disks were made by using a standard single hole paper punch, then they were sterilized by UV irradiation overnight. When cells were at about $60 \%$ confluency, they were fixed and processed according to the procedure outlined in Table 1. This is a modification for microwave of a previously published procedure[2]. To facilitate handling, the samples were put into a 6-well PREP-EZE specimen holder (Ted Pella, Inc. Cat. No.36157-1) which fits into a 60 X 15 mm polypropylene Petri dish (Ted Pella Inc., Cat. No. 36135). Ten ml of solution is used to cover the cells. It is important to use the polypropylene dishes because they are resistant to the solvents used in electron microscopy specimen preparation.

Polymerization. After the last change of pure resin during the infiltration steps, transfer the cells to a flat-bottom capsule that has been partially filled with resin. Make sure that the cells are facing up, i.e., away from the bottom of the capsule. Fill the capsule with resin and seal with Parafilm and a snap cap from a BEEM capsule. Load into a Teflon holder and place in water for polymerization as shown in Giberson [3].

Aclar removal. Once the resin is hardened, remove it from the capsule then use a razor blade to remove excess resin from around the edges of the Aclar $^{\mathrm{TM}}$. Insert the razor blade between the Aclar and resin and it should lift off easily with the cells remaining in the resin.

Other applications. This basic strategy can be used to embed cells in LR White for immunolabelling. The fixatives used would be different and the resin could be cured in about half the time. Another strategy for LR White microwave thin-layer embedding can be found in Lonsdale et al. [4]. 
[1] Kingsley RE, Cole NL. J of Electron Microsc. Tech., 10, 77-85 (1988).

[2] McDonald, K. J. ultrastruct. Res. 86, 107-118 (1984).

[3] Giberson, R.T. In, Microwave Techniques and Protocols, R. Giberson and R. Demaree (Eds.), 13-23, (2001).

[4] J.E. Lonsdale et al., In, Microwave Techniques and Protocols, R. Giberson and R. Demaree (Eds.), 139-153, (2001).

TABLE 1. Microwave Processing Steps for Tissue Culture Cells on Aclar

\section{Processing Step Power Time Vacuum Comments}

Fixation in $2 \%$ glutaraldehyde in $50 \mathrm{mM} \quad 100 \mathrm{~W} \quad$ I min on yes

Cacodylate buffer, $\mathrm{pH} 7.2 \quad 5$ min off ${ }^{\text {a }}$

Rinse in buffer

none $\quad 5 \times 1 \mathrm{~min}$ no $\quad$ Not in microwave

Fixation in $0.05 \% \mathrm{OsO}_{4}$ $+0.08 \% \mathrm{~K}_{3} \mathrm{Fe}(\mathrm{CN})_{6}$ in buffer

Rinse in buffer

Fixation in $0.15 \%$ tannic acid in buffer

Rinse in buffer

Rinse in $\mathrm{dH}_{2} \mathrm{O}$

Dehydration in $35,50,75,95,100,100$ $100 \%$ acetone

Infiltration with $1: 1$ Eponate $12^{\mathrm{b}}$ resin: Acetone

Pure Eponate 12 resin

Polymerization in flat-bottom capsules
100W

1 min on yes

5 min off ${ }^{\text {a }}$

none $\quad 5 \times 1 \mathrm{~min}$ no Not in microwave

none $2 \mathrm{~min}$ no Not in microwave

none $2 \times 1 \mathrm{~min}$ no Not in microwave

none $\quad 3 \times 1 \mathrm{~min}$ no Not in microwave

100W 1 X $40 \mathrm{sec}$ no

each step

250W 1 X 5 min yes

650W $100 \mathrm{~min}$ no Underwater $^{\mathrm{c}}$
350W 2 X 5 min yes

${ }^{a}$ For this fixation step and for the osmium step, it is important to let the cells rest at least 5 minutes before going to the rinse steps.

b 23.5 g Eponate 12, 12.5 g DDSA, 14 g NMA, 0.37 ml DMP-30.

${ }^{\mathrm{c}}$ No need to take out the vacuum chamber, just put the container on top. 